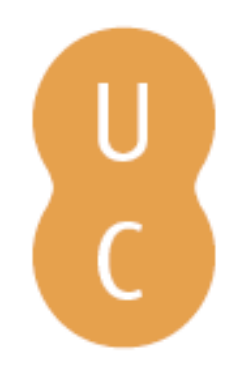

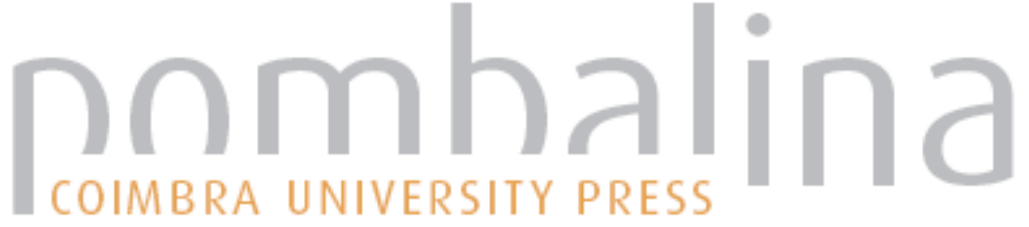

\section{Jardins românticos ou a natureza em simulacro}

Autor(es): Santana, Maria Helena

Publicado por: Imprensa da Universidade de Coimbra

URL

persistente:

URI:http://hdl.handle.net/10316.2/38698

DOI:

DOI:http://dx.doi.org/10.14195/978-989-26-1164-8_21

Accessed : $\quad$ 26-Apr-2023 11:39:09

A navegação consulta e descarregamento dos títulos inseridos nas Bibliotecas Digitais UC Digitalis, UC Pombalina e UC Impactum, pressupõem a aceitação plena e sem reservas dos Termos e Condições de Uso destas Bibliotecas Digitais, disponíveis em https://digitalis.uc.pt/pt-pt/termos.

Conforme exposto nos referidos Termos e Condições de Uso, o descarregamento de títulos de acesso restrito requer uma licença válida de autorização devendo o utilizador aceder ao(s) documento(s) a partir de um endereço de IP da instituição detentora da supramencionada licença.

Ao utilizador é apenas permitido o descarregamento para uso pessoal, pelo que o emprego do(s) título(s) descarregado(s) para outro fim, designadamente comercial, carece de autorização do respetivo autor ou editor da obra.

Na medida em que todas as obras da UC Digitalis se encontram protegidas pelo Código do Direito de Autor e Direitos Conexos e demais legislação aplicável, toda a cópia, parcial ou total, deste documento, nos casos em que é legalmente admitida, deverá conter ou fazer-se acompanhar por este aviso.

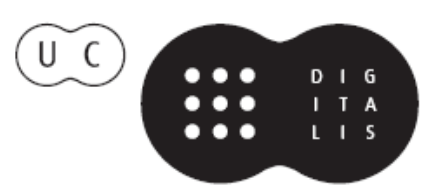


Maria Helena Santana

Universidade de Coimbra / Centro de Literatura Portuguesa

\title{
JARDINS ROMÂNTICOS OU A NATUREZA EM SIMULACRO
}

\begin{abstract}
To build, to plant, whatever you intend, To rear the column, or the arch to bend, To swell the terrace, or to sink the grot; In all, let Nature never be forgot.

But treat the Goddess like a modest fair, Nor overdress, nor leave her wholly bare;
\end{abstract}

O texto em epígrafe, extraído de um poema de Alexander Pope ${ }^{1}$, inspira-se num jardim inglês setecentista (o Stowe Park, perto de Londres), um dos míticos lugares de encontro entre a Poesia e a Natureza no período pré-romântico. Espaço sensorial da rêverie, o jardim inglês, ou landscape garden, constituiu uma das mais celebradas invenções desta época de mutação artística, em que a Natureza se investe de valor cultual. Em rutura com o modelo clássico (Versailles, por exemplo), baseado na regularidade do desenho geométrico, o jardim inglês quer-se orgânico, espontâneo e irregular, à semelhança da paisagem natural; trata-se, ainda assim, de uma figuração idealizada e em grande medida artificial, como a pintura idílica que lhe serve de mediação.

Não há arte verdadeira fora da Natureza - In all, let Nature never be forgot, diz o poema, e dizem todos os poetas e filósofos do Romantismo; mas haverá verdadeira Natureza fora da conceção artística? Nos jardins vegetais, como nos

1 O poema, "An Epistle to the Right Honourable Richard Earl of Burlington" (1731), é um tributo a Richard Boyle, um dos mentores do novo estilo de arquitetura e paisagismo inglês no século xviII. 
jardins literários - observá-lo-emos em Rousseau e em Garrett -, são os olhos do artista que veem a Natureza como Arte, e são as suas composições que exprimem o "sentimento da Natureza"2, o que em ambos os casos transforma a obra do Criador em pura construção cultural.

1. Durante o século xvıI, a conceção e desenho de jardins foi objeto de intenso debate na cultura europeia, em particular nos países onde germinava a sensibilidade romântica. Não se tratou apenas de uma discussão entre profissionais das artes paisagísticas: estava em causa uma ampla reflexão em torno da função estética e moral da Natureza, que envolveu filósofos, teólogos e homens de letras. H. J. Müllenbrock dá-nos circunstanciada informação acerca desse movimento intelectual de que viria a emergir o novo conceito de "jardim inglês"; entre os principais mentores destaca Joseph Addison, pelo seu papel pioneiro em defesa de uma atitude integradora e respeitosa em relação à Natureza³ . Em 1712 o escritor publicou uma série de artigos na revista The Spectator com grande impacto nos círculos culturais britânicos; aí advogava os princípios da irregularidade, da assimetria e da naturalidade ("wildness"), por oposição à formalidade tirânica do jardim francês. Em abono da sua tese, Addison invocava argumentos de índole sociopolítica, contrastando as ideologias dos dois países e a respetiva forma de se relacionarem com o meio ambiente ${ }^{4}$.

Ao longo das décadas seguintes muitos outros intelectuais se posicionaram publicamente, mas o protagonismo caberia sobretudo a Jean-Jacques Rousseau, cuja literatura filosófica impregnou toda a visão romântica da Natureza. Em muitas das suas obras o autor das Rêveries especula sobre a relação harmoniosa (ecológica,

2 Sobre a construção romântica deste conceito vd. Helena Buescu, Incidências do Olhar: percepção e representação (1990), p. 78 e ss.; também no volume Corpo e Paisagem Românticos (2004) se aborda transversalmente o tema.

3 "Addison's critical examination of the formal garden of French origin was persistent and profound and in the final analysis resulted in a reversal of the order of importance attached to nature and art in their respective relation to one another." Heinz-Joachim Müllenbrock, "The English Landscape Garden of the $18^{\text {th }} \mathrm{C}$. and the role of Literature" (versão on-line).

4 "(...)in France a court nobility intent on ostentation and magnificent self-exhibition; in England an aristocracy living in the country and interested in good husbandry. The peculiar nature of the English life-style and, more exactly, of English political conditions [...] since the sovereign manner in which nature was appropriated in the formal French garden was interpreted as a selfrepresentation of royal omnipotence.» (Ibid.). 
como hoje se diria) do ser humano com o meio natural; ou sobre o encontro possível entre "natureza selvagem" e "natureza cultivada". Em Julie ou La Nouvelle Héloïse (1761) este tema ganha uma formulação mais concreta", através da representação de um jardim: trata-se do célebre episódio de Clarens (na Parte IV do romance), em que Julie surpreende o seu amigo Saint-Preux com um arrojado projeto paisagístico. O misterioso Eliseu é um paraíso verdejante e cheio de vida, mas que mantém a aparência de um espaço agreste, um fim-do-mundo absolutamente natural. Entrando por uma porta disfarçada de verdura, Saint-Preux passeia por caminhos tortuosos, bordejados de arbustos, e depara-se com cenários muito variegados: ora tufos de pequenos bosques sombrios, ora viveiros de frutos e flores campestres; ora fios de águas correntes, ora canais e lagos mais profundos, onde centenas de pássaros voam em liberdade. Todo este prodigioso parque natural, num espaço alguns anos antes desértico, fora conseguido com pouco esforço e dinheiro, graças a um hábil trabalho de adaptação dos recursos nativos: a água desviada dum repuxo inútil, os bosques aumentados com pequenos artifícios, os pássaros atraídos por sementeiras naturais.

Segundo M. de Wolmar, marido de Julie, a intervenção humana no Eliseu reduziu-se a um sentido artístico minimalista, por forma a respeitar a (des)ordem própria da Natureza: «Vous ne voyez rien d'aligné, rien de nivelé; [...] la nature ne plante rien au cordeau; les sinuosités dans leur feinte irrégularité sont ménagées avec art pour prolonger la promenade...». Porém o passeio vai revelando até que ponto o efeito-natureza resulta de uma mistificação ("une friponnerie"6), em que a mão do jardineiro, porquanto oculta, ajuda a promover a regulação natural; Julie desempenha no processo o papel principal: "Il est vrai, dit-elle, que la nature a tout fait, mais sous ma direction, et il n'y a rien là que je n'aie ordonné».

5 Logo na Parte I do romance o narrador elogia a perfeita integração do elemento humano na paisagem alpina, enlevado pelo espetáculo artístico que o conjunto proporciona. Cf. William T. Hendel, "The theatrical representation of landscape in Rousseau's La Nouvelle Héloïse" (versão on-line).

6 «Il y a pourtant ici, continuai-je, une chose que je ne puis comprendre; c'est qu'un lieu si différent de ce qu'il était ne peut être devenu ce qu'il est qu'avec de la culture et du soin: cependant je ne vois nulle part la moindre trace de culture; tout est verdoyant, frais, vigoureux, et la main du jardinier ne se montre point; rien ne dément l'idée d'une île déserte qui m'est venue en entrant, et je n'aperçois aucun pas d'hommes. - Ah! dit M. de Wolmar, c'est qu'on a pris grand soin de les effacer. J'ai été souvent témoin, quelquefois complice de la friponnerie. On fait semer du foin sur tous les endroits labourés, et l'herbe cache bientôt les vestiges du travail; on fait couvrir l'hiver de quelques couches d'engrais les lieux maigres et arides; l'engrais mange la mousse, ranime l'herbe et les plantes." La Nouvelle Héloïse, IVe Partie, Lettre XI - à milord Edouard (versão on line). 
A filosofia estética que preside ao ideal rousseauniano do jardim - arte imitativa subtil, propícia à errância dos sentidos - depreende-se ainda das palavras de Wolmar:

L'erreur des prétendus gens de goût est de vouloir de l'art partout, et de n'être jamais contents que l'art ne paraisse; au lieu que c'est à le cacher que consiste le véritable goût, surtout quand il est question des ouvrages de la nature.[...]

Que fera donc l'homme de goût qui vit pour vivre, qui sait jouir de lui-même, qui cherche les plaisirs vrais et simples, et qui veut se faire une promenade à la porte de sa maison? Il la fera si commode et si agréable qu'il s'y puisse plaire à toutes les heures de la journée, et pourtant si simple et si naturelle qu'il semble n'avoir rien fait. Il rassemblera l'eau, la verdure, l'ombre et la fraîcheur; car la nature aussi rassemble toutes ces choses. Il ne donnera à rien de la symétrie; elle est ennemie de la nature et de la variété; [...] la direction n'en sera pas toujours en ligne droite, elle aura je ne sais quoi de vague comme la démarche d'un homme oisif qui erre en se promenant.

Os tratados de Paisagística, muito em voga na época, transcendem igualmente as prosaicas questões decorativas: são antes de mais ensaios de teoria estética, em que as várias artes se fundem sob um mesmo conceito unificador - o sentimento da Natureza. As formas de o produzir variam consoante os autores, mas em geral são unânimes na convocação da Poesia, a par da Pintura, enquanto experiências estéticas subjacentes à arte de criar paisagens. Se a Pintura ensina a olhar, a selecionar, a dar expressão e perspetiva (à Natureza), a Poesia, pelo seu poder evocativo, tem a capacidade de converter a impressão visual em emoção espiritual, levando o fruidor a meditar, mas também a associar imagens e memórias culturais potenciadoras da imaginação. Assim, por exemplo, uma ruína, uma lápide ou uma gruta, colocadas em lugares adequados, convidam a meditar sobre o amor ou a morte e, ao mesmo tempo, a evocar figuras e mitos literários ligados a esses temas-sentimentos. Recolhimento e evasão combinam-se através do que hoje chamaríamos, com Umberto Eco, "passeios inferenciais".

7 Mencione-se-se, entre as obras de referência, John Dixon Hunt, Gardens and the picturesque: studies in the history of landscape architecture, 1994; Louis Hawes, Presences of nature: British landscape, 1780-1830. New Haven, Yale Center for British Art, 1982. 
Um dos mais conhecidos tratados desta índole é De la Composition des Paysages (1877), de René-Louis Girardin, o "autor" do famoso parque de Ermenonville, no norte de França. Como se esperaria num discípulo ardente de J.-J. Rousseau, a Natureza ocupa lugar central na reflexão. Girardin analisa-a quer na perspetiva utilitária, quer na moral, quer sobretudo na estética, à qual dedica o ensaio inicial: "Des Paysages ou De la Nature Choisie". Aí expõe o seu conceito de natureza poética, que se deseja animada e expressiva. A paisagem que interessa ao artista não é a simplesmente natural, por bela e virtuosa que seja, mas aquela que inspira determinadas emoções, e nesse sentido se pode imitar e "compor":

Si la nature mutilée et circonscrite, est triste et ennuyeuse, na nature vague et confuse n'offre qu'un pays insipide; et la nature difforme, n'est qu'un monstre; ce n'est donc qu'en la disposant avec habileté, ou en la choisissant avec goût, qu'on peut trouver ce qu'on a voulu chercher; le véritable effet de Paysages intéressants. ${ }^{8}$

Tal como outros paisagistas do tempo, o autor defende o princípio de que o criador de jardins, sem perder de vista a unidade do conjunto, deve proceder como um pintor, ao seleccionar ambientes particulares com vista a despertar um sentimento doce ou voluptuoso; ou seja, é um criador de quadros que, à semelhança do pintor, selecciona e dispõe os elementos naturais em função do efeito estético a obter nos diversos tableaux. Daqui decorre a dimensão interartística da sua actividade: "Ce n'est donc ni en Architecte, ni en Jardinier, c'est en Poète et en Peintre, qu'il faut composer les paysages, afin d'intéresser tout à la fois, l'oeil et l'esprit»'?

Quanto ao efeito "romântico", que prefere designar por effet pittoresque, consiste essencialmente na introdução de nuances (jogos de luz e perspetiva) por forma a sugerir a variedade e, sobretudo, a espontaneidade, "cette heureuse négligence, qui est le caractère distinctif de la nature et des grâces». Ora, como conclui, citando Rousseau, "tout cela ne peut se faire sans un peu d'illusion». ${ }^{10}$

8 R.L. Girardin, De la composition des paysages ou des moyens d'embellir la Nature autour des habitations, en joignant l'agréable à l'utile, p. 7.

9 Ibid., p. 9.

10 Ibid., p. 10. 
Sendo o jardim uma cópia retocada, e não a natureza virginal, a noção de verdade facilmente desliza para a de verosimilhança, sua congénere ficcional. E sendo o propósito reproduzir perto de nós a paisagem que se encontra em espaços isolados, é lícito ao artista forçar em certa medida a Natureza, fazendo-a acomodar-se à escala e ao efeito desejados. O essencial é que todo o conjunto pareça espontâneo, ocultando a intervenção da mão humana.

2. O parque de Ermenonville, considerado mais "natural" do que o de Stowe, tornou-se um ícone do "jardin pittoresque" (seria aliás o lugar de exílio de J.-J. Rousseau, que aí ficou sepultado). O mesmo termo designava frequentemente o jardim inglês na sua versão bucólica, de influência pictórica. Mas a estética do pitoresco conheceu outras derivações, na esteira de Rousseau. Uma delas é o jardim rústico, que tanto pode revestir a forma de uma pequena quinta ornamental (um "cottage" ou "hameau") como de uma aldeia completa em simulacro. Esta fantasia campestre era muito apreciada pela aristocracia francesa, a começar pela própria rainha Marie Antoinette (lembre-se o famoso Hameau de la Reine, em Versailles). No parque do Castelo de Chantilly, na região da Picardia, edificou-se em 1774 um exemplar surpreendente, composto de sete casinhas de telhado de colmo, em estilo normando, cujos interiores albergavam luxuosos salões de convívio, bilhar e gabinete de leitura. No parque circundante à aldeia-ersatz, os elegantes convivas passeavam a pé ou em piroga por entre canais serpenteantes, com pontes de pedra, e até um penhasco e uma torrente artificiais.

Outra tendência igualmente interessante é o "jardim anglo-chinês", assim designado por se inspirar em modelos de matriz oriental. O conceito original consistia em criar cenografias variegadas, sugestivas de vivências ficcionadas, à maneira dos cenários operáticos ${ }^{11}$; a ideia seduziu desenhadores de jardins europeus, que passaram a incorporar elementos arquitetónicos de diversa índole: é o caso do Parc Monceau, onde se construiu um templo grego, um forte chinês, um moinho holandês, uma pirâmide egípcia, etc.

11 Esta cenografia teatral, existente em alguns jardins de palácios chineses, foi divulgada por viajantes setecentistas como o padre jesuíta Attiret e Sir William Chambers. 
Muitos parques pitorescos se construíram a partir de então por toda a Europa, por vezes conjugando os diferentes estilos (rústico, inglês, anglo-chinês) de forma algo bizarra. Em Portugal pode referir-se o parque de Monserrate, em Sintra, que Lord Byron evocou no poema Childe Harold's Pilgrimage. O jardim paisagístico, iniciado em 1793, por William Beckford, e renovado em meados do século xix, conserva elementos expressivos das duas épocas românticas: aos artifícios originais (a cascata, o cromeleque, o arco de Vathek ${ }^{12}$ ) acrescentou-se mais tarde, por ordem de Sir Francis Cook, uma panóplia de importações exóticas - um arco indiano, um jardim mexicano e outro japonês, etc. ${ }^{13}$

Em termos estéticos, o jardim romântico tardio está de facto bastante longe do característico landscape garden, concebido à imagem das telas idílicas de Claude Lorrain e Nicolas Poussin. Pode mesmo considerar-se que nele predomina um artificialismo barroco, não raro de trompe l'oeil. ${ }^{14}$ Da combinação de elementos europeus e exóticos, antigos e modernos, monumentais e triviais (uma tenda turca ou uma cabana, por exemplo) resulta uma mistura criativa que faz do jardim uma espécie de diaporama. O passeante tinha assim a ilusão de percorrer o mundo inteiro e de contemplar ilustrações em 3D de várias épocas históricas, como hoje se consegue navegando na internet.

3. Passemos agora a Garrett, também ele, a seu modo, autor de jardins.

O culto da natureza selvagem, não domesticada pela mão humana, está bem documentado na ficção garrettiana. Bastaria lembrar a "harmonia suavíssima e perfeita» do Vale de Santarém, que tanto encanta o narrador de Viagens na

12 O cromeleque, composto por vários falsos menires, imita os monumentos megalíticos; o Arco de Vathek alude à conhecida novela gótica de W. Beckford, Vathek, An Arabian Tale (1786).

13 Vd. Ida Kingsbury, Castles, caliphs and christians, a landscape with figures: Monserrate, [Lisboa], The British Historical Society of Portugal - Ass. Amigos de Monserrate, 1994; João Sande de Freitas, Raúl Constâncio, Emma A. Gilbert, Árvores de Monserrate, Sintra, Ass. Amigos de Monserrate /INAPA, 1997.

14 A propósito desta confluência estética diz Georges Gusdorf: "Réaction contre la monotone prédominances des normes, le Romantisme bouscule les lignes, dérange les symétries, agite et boursouffle les contours [...] L'extravagance, le fantastique parasitent le réel; la magie, la féerie surchargent les évidences; notre monde s'ouvre en abîme sur un autre monde [...] comme il arrive dans les fresques et coupoles des églises baroques, où l'âme fidèle se voit offrir le passage vers un ciel aux couleurs de décor d'opéra.» Le Romantisme, vol. I, p. 279. 
Minha Terra. Esse Éden escondido das nações civilizadas ${ }^{15}$ moldou, como sabemos, a beleza natural de Joaninha, sua quase vegetal emanação. Carlos, também nascido no vale, viveu em Inglaterra, país de que recorda os «longos passeios solitários, por aqueles campos sempre verdes, por aquelas colinas coroadas de arvoredo, tapeçadas de relva macia». Mas apesar de admirar as paisagens inglesas, sentir-se-á sempre como uma "planta estrangeira» aclimatada à «branda atmosfera artificial daquela estufa ${ }^{16}$. Da mesma maneira, causam-lhe melancolia os lindos e bem cuidados parques onde se refugia em momentos de crise amorosa; a imagem que então evoca é ainda a do «nosso vale rústico, tão grosseiro e tão inculto [...] no meio daquelas alinhadas e perfeitas belezas da cultura britânica» ${ }^{17}$.

A ideia de "natureza cultivada", no sentido negativo do termo, não é a que mais se associa a um landscape park, mas antes a que convém à semântica do texto. De resto, os parques que a personagem refere em nada se assemelham aos jardins de buxos ao estilo francês; esses, sim, diz o escritor, são reprimidos pelo «regime tirano da tesoira do jardineiro. Barbaramente os tosquiavam em pirâmides, em globos, em esfinges, em retorcidas espirais, em vasos e obeliscos.» A nota crítica pode ler-se numa breve descrição do fragmento ainda inédito $A$ Cruz e o Perjúrio, datado de 1849. No ano seguinte iniciava Garrett o seu último romance, onde esta temática se encontra profusamente desenvolvida.

Helena é uma narrativa interessantíssima, lamentavelmente pouco conhecida ${ }^{18}$. A ação (da primeira parte, pois a obra ficou incompleta) decorre em 1836, num domínio colonial do interior do Brasil ${ }^{19}$. O engenho de Itahé, situado no Recôncavo Baiano, está isolado do mundo, mas os proprietários trouxeram na bagagem a urbanidade da sua educação; e sem abdicarem das origens nobres, souberam adaptar-se ao meio rude em que vivem, e criar laços paternais com a população local. Tendo o casal ascendência diversa, ele português, ela brasileira

15 Cf. Viagens na Minha Terra, edição crítica de Ofélia Paiva Monteiro, pp. 155 e 157-8.

16 Ibid., p. 424-5.

17 Ibid., p. 440.

18 À data sua morte, em 1854, Garrett ocupava-se deste romance, que não concluiu. O fragmento autógrafo foi publicado em 1871, por Carlos Guimarães, e depois reeditado por Teófilo Braga na coleção das Obras Completas do Autor. Está atualmente em preparação uma edição critica do manuscrito, dirigida por Ofélia Paiva Monteiro, que diverge em muitos passos das edições anteriores.

19 Garrett deixou 24 capítulos redigidos, que constituem a primeira parte da história, passada no Brasil. Seguir-se-ia a parte "europeia" da narrativa. Cf. Ofélia Paiva Monteiro, "Helena: os dados e as incógnitas de um enigma romanesco" (1999). 
e meio-índia, formam um curioso exemplo de crioulização cultural. Porém o modelo de sociabilidade que os inspira continua a ser o da aristocracia europeia. Para o concretizar, criaram no sertão uma réplica algo paródica de um palácio anglo-gaulês, a que não falta um butler negro de cabeleira polvilhada e criadas a condizer.

Na construção do palácio e do parque adjacente, os viscondes tiraram partido do espaço envolvente, adaptando as ideias arquitetónicas vindas da Europa à pujante paisagem tropical. A descrição é feita por um visitante francês recém-chegado ao Novo Mundo - um velho general aristocrata, amante da Natureza e especialista em raridades botânicas. Ainda de alma cheia pelas florestas virgens que acabara de percorrer numa exaltante viagem de canoa índia, M. de Bréssac nem acredita no que vê:

Era em verdade para surpreender o quadro magnífico que se desinrolou diante dos olhos do general: um imenso parque inglês, cortado de sinuosas e bem saibradas ruas, com lagos e pontes, kioskis e estátuas, templos e ruínas, com todos os vários e disparatados acidentes e ornamentos que são de rigor em tais casos, e que a arte europea imitou dos caprichos da chinesa.

O francês pasmava do que via: - e a idea de se ver transportado, por um golpe de varinha de condão, de pleno Brasil para Windsor, para Eagley-park ou para Sionhouse, ia-lhe parecendo menos absurda de momento para momento. Sonho, visão, ilusão dos sentidos!... (cap. $\mathrm{V}^{20}$ )

Tratava-se, por conseguinte, de um parque anglo-chinês, na sua mais imaginativa se não mesmo delirante conceção (que inclui ainda torres góticas, pagodes índios, ermidas portuguesas, pórticos mexicanos, agulhas egípcias, mirantes chineses e palhoças de várias nações de África e da América). Percebe-se, por parte do autor, um certo sentido de humor perante o excesso barroco deste tipo de fabricações. O desenquadramento contextual também não escapa ao olhar do visitante, que sente a impressão de estar a viver num conto de fadas. Mas novas surpresas se lhe vão aos poucos revelando:

20 Sigo o texto fixado para a próxima edição critica do manuscrito, cuja grafia conserva marcas estilísticas e epocais. Por não haver ainda uma versão impressa, apenas se indica o capítulo nas citações. 
Foram andando, andando, [...] quando a carruagem, passando por um maciço de árvores altíssimas, desimbocou numa espécie de largo, donde clara e distintamente se via, situada a pouca distância, a meio de uma suave ondulação de terreno, abrigada de três oiteiritos que a rodeiavam, uma verdadeira aldeia de Suíça. Muitas casas piquenas, e, ao parecer, destacadas, com seus tectos de colmo, suas balustradas exteriores de troncos rústicos, formavam o lugarejo, que, para de todo se caracterizar, tinha no meio sua igreja com alto campanário e adro plantado de araucárias, excelsas, brasílicas, imbricatas e desimbricatas: pinheiros tropicais de tão alpino aspecto, que fariam cantar o ranz-des-vaches a qualquer emigrado do Monte Branco ou do San' Bernardo. [...]

- Estranhou o nosso parque inglês no meio destes matos selvagens? Ou talvez estes meus cottages aqui? Estas são maravilhas bem simples, General. Foi um inocente capricho de minha mulher, a que acedi com muito gosto, porque também a mim me seduz o casto esplendor da elegância britânica... (Ibid.)

A um parque romântico, mesmo em solo americano, não podia faltar o seu hameau. A aldeia suíça, vem a saber-se mais tarde, não passa de um extraordinário simulacro, porque as choupanas comunicam entre si, formando na realidade as diversas dependências do palácio, cujo interior é vistoso e requintado. A estratégia de trompe l'oeil estende-se a outros pormenores arquitetónicos - as partes menos nobres da habitação (cozinhas, por exemplo) foram também habilmente ocultadas do lado exterior, para preservar a vista das trivialidades domésticas.

Estes artifícios ilusórios - fruto da moda e do "capricho" feminino - esclarecem-se na manhã seguinte, quando o general é conduzido numa visita guiada à propriedade. Bréssac tem então oportunidade (no capítulo X) de ver o parque à luz do dia, e de admirar, tal como Saint-Preux, a feliz conjunção da arte e da natureza:

O terreno descia em volta da casa num declive suave, todo arrelvado e florido, mas florido numa variedade de cores e de formas que não alcança a imaginação de um europeu.

[...] No centro quási do terreno - um vasto lago natural aperfeiçoado e imbelezado todavia de contínuo se renovava com um riacho considerável que ali vinha ter, e com a saída de muitos regatos que iam serpeando por todo o parque 
levar a frescura e o principal alimento a toda essa pasmosa vegetação, correndo por entre o viço das flores e das relvas. As grandes massas de árvores eram indígenas, primitivas, eram as mesmas das florestas selvagens, mas desassombradas em grupos isolados, e mais belas assim. As menores e muitos dos arbustos eram d' Europa, de África, d'Ásia, da Oceania. Flores e relvas por entre isto tudo, e estátuas e templos.

Dir-se-ia, à primeira vista, uma nova Clarens, implantada em cenário tropical. A originalidade reside no sincretismo da flora mundial e, sobretudo, nos artefactos, "colocados ao pé das árvores e das flores naturais dos países que representavam». Ficamos também a saber, pela explicação condescendente do visconde, que todas as edificações introduzidas são obra da mulher: "coisas da minha pobre Maria Teresa... Coitada! que tão brasileira é no coração, mas tem a cabeça anglo-gala». Rousseau não teria apreciado a solução ${ }^{21}$, por muito que se insista na harmonia formal do conjunto. E Garrett? O texto não permite uma resposta unívoca, dado que há alguma ironia latente em certos comentários elogiosos. Não há dúvidas, no entanto, de que o Eliseu de Julie é o ghost text do jardim de Itahé, como se pode comprovar pelos passos seguintes:

- Premièrement, repris-je, je ne comprends point comment avec de la peine et de l'argent on a pu suppléer au temps. Les arbres... - Quant à cela, dit M. de Wolmar, vous remarquerez qu'il n'y en a pas beaucoup de fort grands, et ceux-là y étaient déjà. [...] - Eh bien! dis-je, puisque vous voulez que tous ces massifs, ces grands berceaux, ces touffes pendantes, ces bosquets si bien ombragés, soient venus en sept ou huit ans, et que l'art s'en soit mêlé, j'estime que, si dans une enceinte aussi vaste vous avez fait tout cela pour deux mille écus, vous avez bien économisé. - Vous ne surfaites que de deux mille écus, dit-elle; il ne m’en a rien coûté. - Comment, rien? - Non, rien; à moins que vous ne comptiez une douzaine de journées par an de mon jardinier, autant de deux ou trois de mes

${ }^{21}$ «Je me mis à parcourir avec extase ce verger ainsi métamorphosé; et si je ne trouvai point de plantes exotiques et de productions des Indes, je trouvai celles du pays disposées et réunies de manière à produire un effet plus riant et plus agréable.) (Palavras de Saint-Preux, confirmadas depois por M. de Wolmar, a propósito do Parque de Staw:) "C'est un composé de lieux très beaux et très pittoresques dont les aspects ont été choisis en différents pays, et dont tout paraît naturel, excepté l'assemblage, comme dans les jardins de la Chine dont je viens de vous parler.» 
gens, et quelques-unes de M. de Wolmar lui-même, qui n'a pas dédaigné d'être quelquefois mon garçon jardinier.» [...] Je vis alors qu'il n'avait été question que de faire serpenter ces eaux avec économie en les divisant et réunissant à propos, en épargnant la pente le plus qu'il était possible, pour prolonger le circuit et se ménager le murmure de quelques petites chutes.

- 'Vejo que admira o nosso parque, general' disse o visconde.

- 'É um prodígio, é a coisa mais bela que tenho visto.'

- 'Há aí muita coisa bela com efeito. Mas eu não tenho aqui outro mérito senão o de ter mondado com alguma arte, e sinceramente digo que me parece com algum gosto também, as demasias da vegetação natural. Cortei por onde fazia jeito, deixei todas as árvores mais belas, até os próprios arbustos, as lianas e o mato baixo deixei em muita parte. Fiz sangrar o rio próximo, e derivar dele essa ribeira que aí vem ter, porque a água da lagoa era quási estagnada. E com um pouco de capim que por aí se plantou, umas socas de bananeiras que por aí se meteram, umas laranjeiras e uns limoeiros que se dispuseram com algum gosto, e um bom jardineiro que mandei vir de Escócia, e que ao princípio fazia tudo atravessado, mas por fim calhou com os descontos do clima, - tudo ficou feito em menos de dous anos. ${ }^{22}$

Entre a paisagem adâmica, tantas vezes celebrada nos textos românticos, e o "prodígio" da contrafação há uma distância cultural que não se pode ignorar. Se, perante a verdadeira natureza, tanto Saint-Preux como Bréssac experimentam o sentimento de êxtase, já a natureza aclimatada lhes suscita surpresa, como cópia perfeita que aparenta ser. Arte mimética, o jardim romântico participa do princípio da ficção, levando o espetador a ver o objeto criado como se fosse real. Mas o objeto contrafeito não se limita a reproduzir o original: como todo o simulacro artístico, produz um efeito semiótico de ordem hiperbólica que substitui, aperfeiçoa e acaba por superar o próprio "real". O sentimento da natureza, já de si subjetivo, converte-se assim numa experiência lúdica, a exigir um espetador disposto a entrar no jogo.

22 Tal como em La Nouvelle Héloïse, o passeio em Itahé termina com a chegada à lagoa, cuja vitalidade desfaz o acesso de melancolia do visitante: "Ali eram tantos os pássaros aquáticos e tal a bulha que fizeram ao chegar dos dois, que forçoso foi ao velho viajante sair do seu pesadelo acordado, e deixar-se distrair pela folgazã alegria da natureza». (Cap. X). 


\section{Post scripum}

Esta incursão botânico-literária tem uma motivação pessoal: a alegre memória das tardes partilhadas com a Doutora Ofélia, em 2010 e 2011, tentando decifrar a "inrevezada" caligrafia de Garrett. Recordo em particular o manuscrito de Helena e as plantas e aves exóticas do jardim de Itahé: em luta com as palavras, aos poucos conseguimos ligar um nome a cada pássaro, uma forma a cada árvore e um aroma a cada flor... e assim o landscape garden foi ganhando cor. 


\section{BIBLIOGRAFIA}

BUESCU, Helena Carvalhão, (1990), Incidências do olhar: percepção e representação. Natureza e registo descritivo na evolução do romance romântico (Portugal, França, Inglaterra), Lisboa, Caminho. , et al. (org.), (2004), Corpo e Paisagem Românticos, Lisboa, FLUL-Edições Colibri.

GARRETT, Almeida, (1963), Helena. Obras de A. Garrett, vol. I, Porto, Lello \& Irmão, Editores.

_-_, (2010), Viagens na Minha Terra, edição crítica de Ofélia Paiva Monteiro, Lisboa, INCM.

GIRARDIN, René-Louis, (1777), De la composition des paysages ou des moyens d'embellir la Nature autour des habitations, en joignant l'agréable à l'utile. Genève-Paris, Chez P. M. Delaguette.

GUSDORF, Georges, (1993), Le Romantisme, 2 vols., Paris, Payot et Rivages.

HAWES, Louis, (1982), Presences of Nature: British landscape, 1780-1830. New Haven, Yale Center for British Art.

HENDEL, William T., (2004), "The theatrical representation of landscape in Rousseau's La Nouvelle Héloïse", in Paroles Gelées (UCLA), vol. 21, 1, pp. 47-52 http://escholarship. org/uc/item/40q7279q;isessionid=7AB1A27A511B17122955C79AA4F8E763

HUNT, John Dixon, (1994), Gardens and the picturesque: studies in the history of landscape architecture, Cambridge, Mass.,The MIT Press.

MONTEIRO, Ofélia Paiva, (1999), "Helena: os dados e as incógnitas de um enigma romanesco", in Leituras. Revista da Biblioteca Nacional, 4, pp. 147-174.

MÜLLENBROCK, Heinz-Joachim, (2006), "The English Landscape Garden of the $18^{\text {th }}$ C. and the role of Literature", EESE 4/2006 http://webdoc.gwdg.de/edoc/ia/eese/artic26/garden/4_2006.html

ROUSSEAU, J.-J., Julie ou la Nouvelle Hélö̈se. Oeuvres complètes de J.-J. Rousseau, tome II, Paris, A. Houssiaux, 1852-1853. [texte établi par René Pomeau] http://fr.wikisource.org/wiki/Julie_ou_la_Nouvelle_Héloïse 